\title{
The easternmost discovery of the Mediterranean weevil Pachyrhinus lethierryi (Coleoptera, Curculionidae, Entiminae): Is a further invasion possible?
}

\author{
Yakov N. Kovalenko², Evgeniy N. Akulov³, Nikolai Yunakov' \\ I University of Oslo, Natural History Museum, Department of Zoology, P.O. Box 1172, Blindern, NO-0318 \\ Oslo, Norway 2 A.N. Severtsov Institute of Ecology and Evolution, Russian Academy of Sciences, 33 Leninskiy \\ prosp., 119071, Moscow, Russia 3 All-Russian Plant Quarantine Center, Krasnoyarsk branch, 31A Maerchak \\ str., 660075, Krasnoyarsk, Russia \\ Corresponding author: Nikolai Yunakov (n.yunakov@gmail.com)
}

Academiceditor:M.Alonso-Zarazaga|Received29September2018|Accepted4November2018|Published28November2018

http://zoobank.org/74511E9C-E910-4313-A6A5-1E26AE7B8A67

Citation: Kovalenko YN, Akulov EN, Yunakov N (2018) The easternmost discovery of the Mediterranean weevil Pachyrhinus lethierryi (Coleoptera, Curculionidae, Entiminae): Is a further invasion possible? ZooKeys 799: 89-93. https://doi.org/10.3897/zookeys.799.29934

\begin{abstract}
Pachyrhinus lethierryi (Desbrochers des Loges, 1875) is a Mediterranean weevil species that has become remarkably well known as a result of a series of recent introductions across Western and Central Europe. This species has recently reached Asia Minor and the Crimean Peninsula, as confirmed by several new records. The vectors of invasion in Crimea and possible further expansion are suggested.
\end{abstract}

\section{Keywords}

Asia Minor, Crimea, invasive species, new record, Polydrusini, weevils

\section{Introduction}

The native range of Pachyrhinus lethierryi is along the Mediterranean coast of France, Corsica, Sardinia, and Sicily (Hoffmann 1950). Since the 1980s, P. lethierryi has spread rapidly as an adventive species into many European countries (Germann et al. 2005, 2013; Scholze 2007; Heijerman 2008; Delbol 2009; Barclay and Morris 2011, Yunakov 2013; Çerçi 2016; Germann and Braunert 2018). 


\section{Material and methods}

For spatial analysis we used occurrence datasets from the Global Biodiversity Information Facility (GBIF 2018) and the Ukrainian Biodiversity Information Network (UkrBIN 2018). The beetle and genitalia were photographed with a Zeiss SteREO Discovery.V20 microscope equipped with Canon EOS 5D Mark III camera. Spatiotemporal data have been mapped in QGIS v. 3.2 using a Google Maps satellite imagery layer. Male genitalia were placed in a transparent polypropylene tube with glycerine and pinned to the underside of the card with the mounted specimen.

\section{Collections}

RPQC All-Russian Plant Quarantine Center, Moscow

ZMUN Zoological Museum University of Oslo, Norway

\section{Results and discussion}

\section{Pachyrbinus (Pachyrbinus) lethierryi lethierryi (Desbrochers des Loges, 1875)} Figures 1-3

Material examined. 1 f, Crimea, Yalta, Mt Dorsan, 44.5030N; 34.1601E, beating from Thuja occidentalis, N. Yunakov leg., 01.ix.2013 (ZMUN); $1 \mathrm{~m}$, Crimea, Sevastopol, Uchkuyevka, 44.6408N; 33.5367E, E.N. Akulov leg., 1-7.vi.2017 (RPQC).

Recent records indicate that $P$. lethierryi is continuing its expansion to eastward. The northernmost record to date is from Magdeburg, Germany, in 2013. In 2018, it was first recorded in Asia Minor at Urla, İzmir, Turkey (UkrBIN 2018). All specimens were found in urban areas with numerous Cupressus, Thuja, and Juniperus trees in neighbouring properties. These plants are known as the principal hosts for $P$. lethierryi (Hoffmann 1950; Alziar 1977; Germann et al. 2005; Plant et al. 2006) and are considered to be the main vectors for the further spread of P. lethierryi (Heijerman 2008). Recent records from Crimea are obviously in line with a general trend of this species' dispersal northward and eastward with commercial ornamental plants. However, we have no proof that $P$. lethierryi has established a viable population in Crimea. Thus, it may be preliminarily characterized as a "Robinson Crusoe species", that is, one that was accidentally introduced without further naturalization. A remarkable feature of adventive populations of P. lethierryi, along with some invasive Otiorhynchus species, is that no specimens are known from natural habitats.

In Asia Minor and Crimea, P. lethierryi can be easily confused with some species of the genera Dichorrhinus Desbrochers des Loges, 1875 and Rhinoscythropus Desbrochers des Loges, 1895. The following key is given to distinguish P. lethierryi from similar species: 

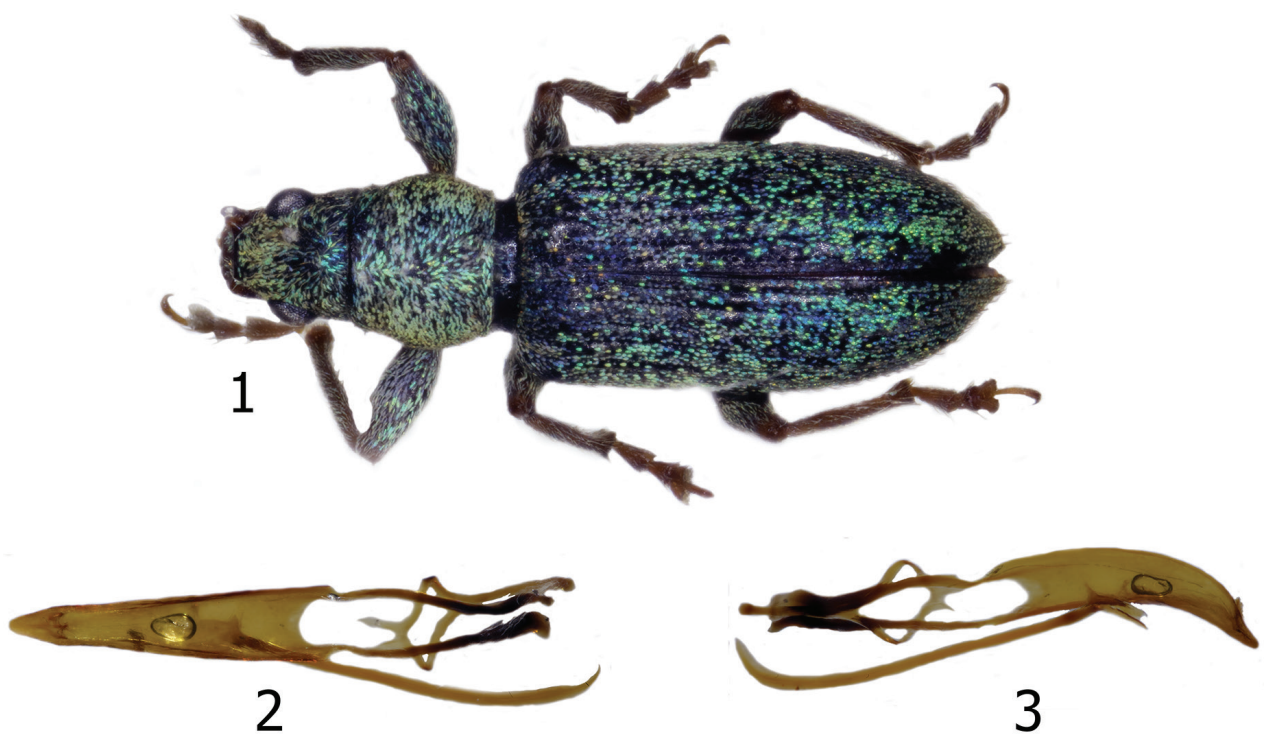

Figures I-3. Pachyrhinus lethierryi. I Male, dorsal habitus 2 Aedeagus, dorsal view $\mathbf{3}$ Aedeagus, lateral view.

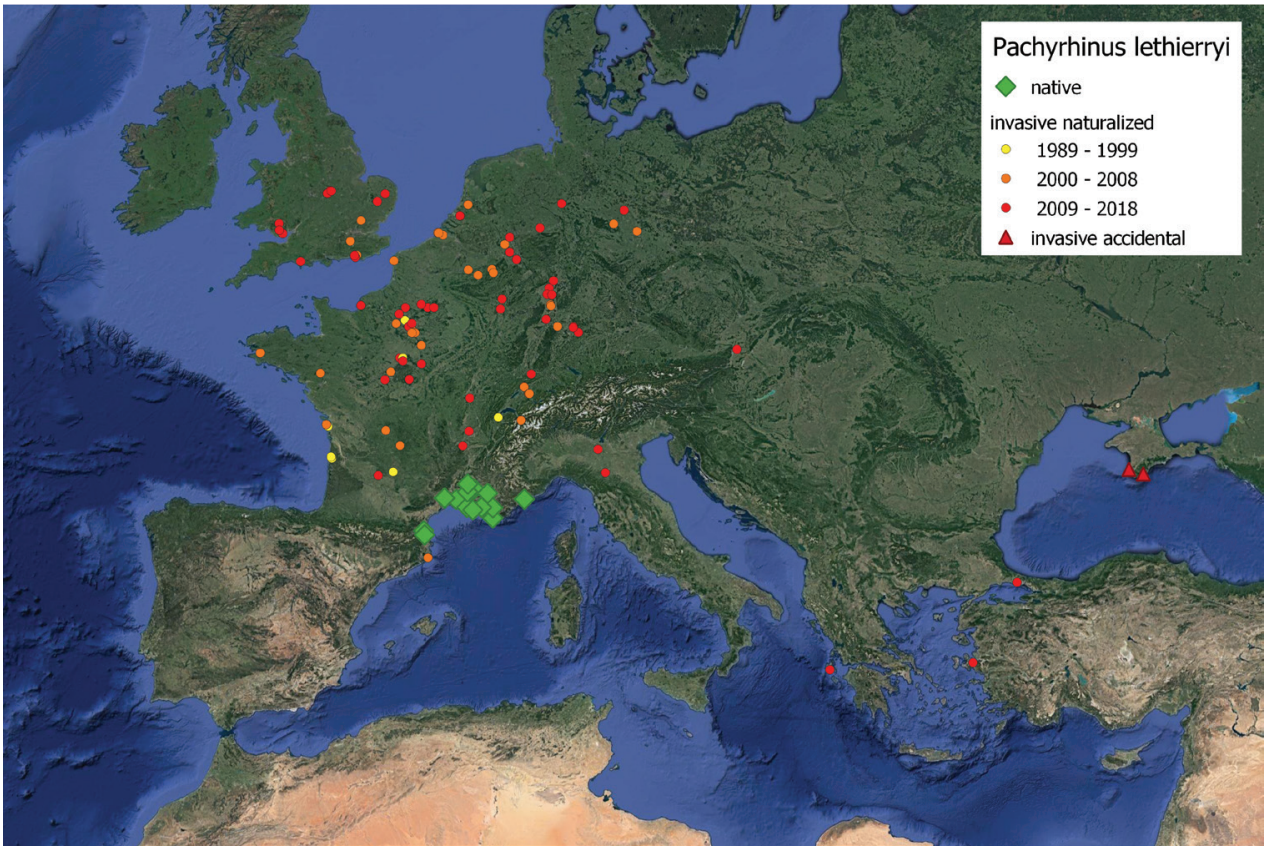

Figure 4. Occurrence pattern of Pachyrhinus lethierryi. The yellow through orange to red gradient indicates the chronology of invasion from 1989 to present. 
1 Antennal scrobes laterally open. Epifrons (rostral dorsum) between antennal base as wide as distance between eyes. Antennal scape slightly curved. Median lobe regularly narrowed apically, without subapical lateral callosities 2

- $\quad$ Antennal scrobes dorsally open. Epifrons (rostral dorsum) between antennal base as wide as $1 / 2$ distance between eyes. Antennal scape strongly curved. Median lobe constricted before apex, with subapical lateral callosities ........ 3

2 Scales ovate, uniformly green. Frons (nasal plate) squamulate. Body with black erect or suberect pilosity. Body length to $5 \mathrm{~mm}$

Pachyrhinus lethierryi (Desbrochers des Loges, 1875)

- $\quad$ Scales piliform, cupreous, forming spotty pattern on elytra. Body without black erect or suberect pilosity. Body length greater than $6 \mathrm{~mm}$

Pachyrhinus squamulosus (Herbst, 1795)

3 Frons (nasal plate) bare. Longitudinal diameter of eye equals 0.5-0.6 times distance between eyes............ Dichorrbinus Desbrochers des Loges, 1875

- $\quad$ Frons (nasal plate) squamulate. Longitudinal diameter of eye equal to distance between eyes Rhinoscythropus vespertilio (Faust, 1884)

\section{Acknowledgements}

We thank Christoph Germann (Naturhistorisches Museum Basel) who provided to us occurrence data from his database, and Alexander Khaustov (Nikitsky Botanical Garden, Yalta) and Mykola Kovblyuk (V.I. Vernadsky Taurida National University, Simferopol) for facilitating the fieldwork in Crimea in 2013. Max Barclay (Natural History Museum, London) checked the English and commented on the manuscript. The study of the second author was supported by the Russian Science Foundation, project No. 16-14-10031.

\section{References}

Alziar G (1977) Sur l'élévage de Scythropus lethierryi Desbr. (Coleoptera, Curculionidae). Riviera Scientifique 1: 19-24.

Barclay MVL, Morris MG (2011) Pachyrhinus lethierryi (Desbrochers) (Curculionidae) in Dorset. Coleopterist 20(2): 54.

Çerçi B (2016) First records of Pachyrhinus lethierryi lethierryi (Desbrochers, 1875) and Otiorhynchus armadillo (Rossi, 1792) (Coleoptera: Curculionidae: Entiminae) from Turkey. Biharean Biologist 10(2): 141-143.

Delbol M (2009) Présence de Pachyrhinus lethierryi (Desbrochers 1875) (Coleoptera: Curculionidae) en Belgique. Entomologie faunistique - Faunistic Entomology 61(4): 163-164.

GBIF (2018) Pachyrhinus lethierryi Global Biodiversity Informaiton Facility occurrence download. https://doi.org/10.15468/dl.5eamod [Accessed on: 2018-9-5] 
Germann C (2013) Pachyrhinus lethierryi (Desbrochers, 1875)-Primera cita para la fauna Ibérica (Coleoptera, Curculionidae). Boletín de la Sociedad Entomológica Aragonesa 53: 321-322.

Germann C, Braunert C (2018) Contribution to the weevils of Kefalonia (Greece) (Coleoptera, Curculionoidea). Parnassiana Archives 6: 25-40.

Germann C, Bahr F, Bayer C, Behne L, Müller G, Müller U, Sprick P, Winkelmann H (2005) Nachweis von Pachyrhinus lethierryi (Desbrochers, 1875) und Otiorhynchus crataegi Germar, 1824 am Niederrhein (Deutschland: Rheinland) (Curculionidae: Entiminae: Polydrusini). Weevil News 28: 1-3.

Heijerman T (2008) De snuitkever Pachyrhinus lethierryi nieuw voor Nederland (Coleoptera: Curculionidae). Nederlandse Faunistische Mededelingen 28: 35-39.

Hoffmann A (1950) Coléoptères Curculionidae. 1ère partie. Faune de France. Vol. 52. Le Chevalier, Paris, 486 pp.

Plant CW, Morris MG, Heal NF (2006) Pachyrhinus lethierryi (Desbrochers, 1875) (Curculionidae) new to Britain and evidently established in south-east England. Coleopterist 15(2): 59-65.

Scholze P (2007) Ein Beitrag zur Erfassung der Käferfauna Sachsen-Anhalts (Insecta, Coleoptera). Entomologische Nachrichten und Berichte 51: 131-134.

UkrBIN (2018) Pachyrhinus lethierryi (Desbrochers des Loges, 1875) Dataset. Ukrainian Biodiversity Information Network. http://ukrbin.com/index.php?id=19558 [Accessed on: 2018-9-1]

Yunakov NN (2013) Polydrusini. In: Löbl I, Smetana A (Eds) Catalogue of Palaearctic Coleoptera, Vol. 8. Brill, Leiden, 364-375. http://doi.org/10.1163/9789004259164 